\title{
Sukses pengoperasian pukat cincin Sinar Lestari 04 dengan alat bantu rumpon yang beroperasi di Perairan Lolak Provinsi Sulawesi Utara
}

\author{
Success of Sinar Lestari 04 purse seine operation around a fish aggregating device in \\ Lolak waters, North Sulawesi Province
}

\author{
ORISON S. KEFI", ELOF M. KATIANDAGHO dan ISROJATY J. PARANSA. \\ Program Studi Pemanfaatan Sumberdaya Perikanan, Fakultas Perikanan dan Ilmu Kelautan, \\ Universitas Sam Ratulangi, Manado 95115
}

\begin{abstract}
The success of purse seine operation depends on fisherman's knowledge about technical operation factors and oceanographic parameters that directly affect the behavior of target fish around a fish aggregating device. Purposes of this research were to study the operating success with measured parameters included circular setting speed, pursing speed, current, sea surface temperature and salinity in their relation to the catches obtained during fishing operations. The result of this research shows that purse seine operation using a fish aggregating device, circular setting speed has little effect because the target fish have already aggregated under the fish aggregating device, the pursing speed has a greater effect on the catch because the purse line running under the school of fish, therefore faster pursing speed is needed to close fast the bottom of the net. The catches are frigate mackerel, skipjack tuna, scad, trevally and yellow fin tuna.
\end{abstract}

Keywords: purse seine, fish aggregating device, fishing operation, temperature, salinity

\begin{abstract}
ABSTRAK
Sukses pengoperasian pukat cincin bergantung pada pengetahuan nelayan mengenai faktor teknis operasi dan faktor oseanografi yang berpengaruh langsung pada tingkah laku jenis ikan yang menjadi tujuan penangkapan di sekitar rumpon. Penelitian ini bertujuan untuk mempelajari sukses tersebut dengan parameter yang diukur yaitu kelajuan melingkar jaring, kelajuan penarikan tali kolor, arus, suhu dan salinitas permukaan laut dalam hubungannya dengan hasil tangkapan yang diperoleh selama operasi penangkapan. Hasil penelitian ini menunjukkan bahwa pengoperasian pukat cincin dengan alat bantu rumpon, kelajuan melingkar jaring memiliki pengaruh yang kecil karena ikan-ikan yang menjadi tujuan penangkapan sudah berkumpul di bawah rumpon, kelajuan penarikan tali kolor memiliki pengaruh yang besar terhadap hasil tangkapan karena tali kolor akan ditarik melewati bawah gerombolan ikan sehingga kelajuan penarikan tali kolor yang lebih cepat akan lebih baik untuk menutup bagian bawah jaring. Hasil tangkapan yang diperoleh yaitu ikan tongkol, ikan cakalang, ikan layang, ikan selar, dan ikan tuna sirip kuning.
\end{abstract}

Kata-kata kunci: pukat cincin, rumpon, operasi penangkapan, suhu, salinitas

\section{PENDAHULUAN}

Usaha pengembangan perikanan merupakan upaya untuk menaikkan produksi perikanan yang dapat ditempuh dengan memperbesar daya tangkap, yang berarti menaikkan kemampuan operasi penangkapan ikan disertai dengan penggunaan

\footnotetext{
*Penulis untuk penyuratan; email: orison.kefi@yahoo.co.id
}

teknologi yang lebih baik. Alat tangkap pukat cincin, di Sulawesi Utara lebih dikenal dengan nama "soma pajeko" merupakan salah satu alat tangkap yang memiliki perkembangan yang baik, karena alat tangkap ini sangat efektif untuk menangkap ikan pelagis kecil yang bergerombol dengan kepadatan yang tinggi (Katiandagho 1989). 
Walaupun sudah dibuat alat tangkap dengan bahan yang terpilih dan sudah memenuhi persyaratan yang dikehendaki serta konstruksi alat tangkap yang baik, tetapi jika nelayan yang mengoperasikan alat tangkap tersebut terbatas pengetahuannya tentang faktor teknis alat tangkap itu sendiri dan tingkah laku ikan yang menjadi target tangkapan di sekitar rumpon, maka usaha penangkapan tentu tidak akan berhasil dengan baik, yang akan berdampak pula pada jumlah hasil tangkapan yang sedikit.

Sukses operasi penangkapan sangat bergantung pada kecepatan melingkari gerombolan ikan, yang tujuannya untuk memagari gerak ikan secara horizontal; kecepatan penarikan tali kolor, untuk menutup bagian bawah jaring; serta keterampilan nelayan pada saat pengoperasian. Faktor oseanografi seperti arus, suhu, dan salinitas juga ikut berpengaruh pada tingkah laku ikan di sekitar rumpon tersebut. Penelitian ini bertujuan untuk mempelajari sukses tersebut dengan parameter yang diukur yaitu kelajuan melingkar jaring, kelajuan penarikan tali kolor, arus, suhu dan salinitas permukaan laut dalam hubungannya dengan hasil tangkapan yang diperoleh selama pengoperasian.

\section{METODE PENELITIAN}

\section{Metode pengambilan data}

Metode yang digunakan dalam pengambilan data adalah metode deskriptif berdasarkan studi kasus. Teknik pengambilan data dilakukan dengan pengamatan langsung yaitu mengukur konstruksi soma pajeko dan kasus yang dipelajari yaitu pengoperasian soma pajeko berdasarkan parameter-parameter yang diukur yaitu menghitung kelajuan melingkar jaring dan kelajuan penarikan tali kolor, serta mengukur beberapa faktor oseanografi yaitu suhu, salinitas, arah dan kecepatan arus pada permukaan laut.

\section{Analisa data}

Data yang diambil kemudian diolah dengan menggunakan formula sebagai berikut:

Hang-in ratio pada setiap bagian jaring (Nomura dan Yamazaki, 1977),

$$
\mathrm{E}^{\prime}=\frac{\mathrm{L}-\mathrm{I}}{\mathrm{L}} \times 100 \%
$$

dimana:

$$
\mathrm{E}^{\prime}=\text { Hang-in ratio }(\%)
$$

$$
\begin{aligned}
\mathrm{L}= & \text { Panjang jaring dalam keadaan stretch } \\
& \text { mesh }(\mathrm{m}) \\
\mathrm{I}= & \text { Panjang tali ris }(\mathrm{m})
\end{aligned}
$$

Kedalaman jaring setelah tertata (Nomura dan Yamazaki, 1977),

$$
\mathrm{d}=\mathrm{n} \cdot \mathrm{m} \sqrt{2 \cdot \mathrm{E}^{\prime}-\left(\mathrm{E}^{\prime}\right)^{2}}
$$

dimana:

$$
\begin{aligned}
& \mathrm{d}=\text { Kedalaman jaring yang tertata }(\mathrm{m}) \\
& \mathrm{n}=\text { Jumlah mata jaring ke arah dalam } \\
& \mathrm{m}=\text { Besar mata jaring }(\mathrm{cm}) \\
& \mathrm{E}^{\prime}=\text { Hang-in ratio }(\%)
\end{aligned}
$$

Kelajuan melingkar jaring menggunakan formula (Sears dan Soedarjana, 1970) yang telah disesuaikan,

$$
\operatorname{Vmj}=\frac{S m j}{t}
$$

dimana:

$$
\begin{aligned}
\mathrm{Vmj}= & \begin{array}{l}
\text { Kelajuan melingkar jaring } \\
\text { (meter/detik) }
\end{array} \\
\mathrm{Smj}= & \text { Lintasan melingkar jaring (meter) } \\
\mathrm{T}= & \text { Waktu yang dibutuhkan selama } \\
& \text { lintasan (detik) }
\end{aligned}
$$

Kelajuan penarikan tali kolor menggunakan formula

$$
\text { Vmtk }=\frac{0,5 \times \text { Smtk }}{\mathrm{t}}
$$

dimana:

$$
\begin{aligned}
\mathrm{Vmtk}= & \begin{array}{l}
\text { Kelajuan penarikan tali kolor } \\
\text { (meter/detik) }
\end{array} \\
\mathrm{Smtk}= & \text { Panjang tali kolor (meter) } \\
\mathrm{T}= & \begin{array}{l}
\text { Waktu yang dibutuhkan selama } \\
\text { penarikan (detik) }
\end{array}
\end{aligned}
$$

Nilai 0,5 adalah tetapan untuk penarikan tali kolor dari dua arah sekaligus.

Kecepatan arus permukaan menggunakan formula

$$
\mathrm{V}=\frac{\mathrm{s}}{\mathrm{t}}
$$

dimana:

$$
\begin{aligned}
& \mathrm{V}=\text { Kecepatan arus (meter/detik) } \\
& \mathrm{S}=\text { Jarak tempuh (meter) } \\
& \mathrm{T}=\text { Waktu tempuh (detik) }
\end{aligned}
$$

Data yang diolah kemudian dianalisa untuk mengetahui sukses operasi penangkapan berdasarkan jumlah hasil tangkapan yang diperoleh selama pengoperasian dan disimpulkan berdasarkan faktor-faktor yang secara langsung mempengaruhi operasi penangkapan tersebut. 


\section{HASIL DAN PEMBAHASAN}

\section{Deskripsi unit alat tangkap soma pajeko}

Konstruksi pukat cincin yang digunakan terdiri dari beberapa komponen yaitu pelampung, tali temali, jaring, pemberat, dan cincin. Pada hubungan antara tali ris dan tali samping dengan jaring terdapat serampat yang berfungsi sebagai penguat jaring. Bagian-bagian soma pajeko yang diteliti terdiri dari bagian sayap, bagian bahu, bagian perut dan bagian kantong.

\section{Bahan jaring}

Bahan jaring untuk semua tubuh jaring dan bagian serampat terbuat dari Polyamide continous filament (PA cf). Ukuran benang dan besar mata jaring berbeda-beda untuk setiap bagian jaring. Pada bagian sayap digunakan nomor benang 210 $\mathrm{D} \times 9$ dan besar mata 2 inci $(1$ inci $=2,54 \mathrm{~cm})$, bagian bahu digunakan nomor benang $210 \mathrm{D} \times 12$ dengan besar mata 1,5 inci, bagian perut menggunakan nomor benang $210 \mathrm{D} \times 15$ dengan besar mata 1,25 inci, bagian kantong menggunakan nomor benang $210 \mathrm{D} \times 18$ dan nomor benang $210 \mathrm{D} \times 24$ dengan besar mata 1 inci dan bagian serampat atau penguat jaring menggunakan nomor benang $210 \mathrm{D} \times 24$ dengan besar mata 2 inci.

\section{Tali temali}

Tali temali yang digunakan adalah dari bahan Polyethylene (PE). Tali ris atas berfungsi untuk menggantung jaring di bagian atas yang berpasangan dengan tali pelampung, yang mana tali pelampung dimasukkan melalui lubang pelampung. Tali ris bawah berfungsi untuk menahan jaring bagian bawah yang berpasangan dengan tali pemberat untuk menggantung pemberat. Pada tali pemberat dipasang bridle untuk menggantungkan cincin, dan cincin ini berfungsi sebagai tempat lewatnya tali kolor. Tali samping terdiri dari dua utas tali yang panjangnya sesuai dengan dalam jaring pada bagian sayap, sedangkan tali tarik diikat pada ujung tali pelampung dan tali ris, tali tarik ini hanya dipasang pada salah satu ujung sayap jaring. Tali kolor dipasang melalui cincin yang berfungsi untuk menarik dan mengumpulkan cincin sehingga alat tangkap membentuk kantong pada saat ditarik ke samping kapal. Tali pelampung dan tali ris atas berdiameter $12 \mathrm{~mm}$, tali ris bawah, tali pemberat dan tali samping berdiameter $10 \mathrm{~mm}$, tali tarik berdiameter $18 \mathrm{~mm}$, tali bridle berdiameter $12 \mathrm{~mm}$ sedangkan tali kolor berdiameter $32 \mathrm{~mm}$.

\section{Pelampung}

Pelampung yang digunakan ada dua tipe yaitu $\mathrm{F}$ 803 A berwarna putih dengan gaya apung 740,26 gf dan D-8 T berwarna kuning dengan gaya apung 1900 gf. Pelampung berwarna putih dipasang pada bagian sayap jaring, sedangkan pelampung berwarna kuning dipasang dari bagian bahu sampai kantong jaring. Selain pelampung jaring ada juga pelampung tanda berbentuk silinder berwarna putih terbuat dari gabus dipasang pada salah satu ujung alat tangkap.

\section{Pemberat}

Pemberat yang digunakan dari bahan timah hitam $(\mathrm{Pb})$ dengan berat di udara $350 \mathrm{gr}$, berbentuk buah pinang, dipasang pada tali pemberat dengan jarak pemasangan antar pemberat $20 \mathrm{~cm}$.

\section{Cincin}

Cincin yang digunakan dari bahan kuningan $(\mathrm{Br})$ berbentuk bulat dengan diameter lingkaran luar $150 \mathrm{~mm}$ dan berat di udara 650 gr digantung dengan tali bridle sepanjang $50 \mathrm{~cm}$ yang diikatkan pada tali pemberat sebanyak 91 buah.

\section{Alat bantu dan alat tambahan penangkapan}

\section{Rumpon}

Rumpon adalah alat bantu yang dipasang di perairan untuk memudahkan dalam penentuan daerah penangkapan dan juga memudahkan dalam proses pengoperasian sebagai pengumpul ikan. Pada bagian bawah rumpon tersebut terdapat "gara-gara" dari daun lontar (Borassus flabellifer) sebagai atraktor untuk memikat dan mengumpulkan ikan-ikan kecil.

\section{Pancing tangan}

Pancing tangan atau oleh nelayan setempat disebut pancing goyang-goyang, dioperasikan pada saat kapal tiba di rumpon. Hasil tangkapan digunakan sebagai indikator dalam memprediksi banyaknya ikan dan jenis ikan yang berada di sekitar rumpon.

Skiff boat

Skiff boat berfungsi sebagai patokan untuk menentukan jarak penawuran jaring, memudahkan penyelam yang bekerja di dalam air agar sewaktuwaktu dapat beristirahat, untuk menarik kapal dari samping, dan juga membantu menarik dan mengatur pelampung apabila banyak pelampung yang terkumpul dan tidak beraturan di perairan. Skiff boat juga berfungsi untuk mengatur rumpon setelah selesai proses operasi penangkapan. Pada 
skiff boat dipasang mesin penggerak berupa motor tempel $40 \mathrm{PK}$

\section{Mesin takal}

Mesin takal sebagai alat tambahan penangkapan berfungsi untuk menarik tali sehingga memudahkan pekerjaan ABK di atas kapal. Fungsi utama mesin takal adalah untuk menarik tali kolor dan mengangkat alat tangkap ke atas kapal. Selain itu, mesin takal digunakan untuk menurunkan dan menaikan skiff boat.

Boom yang berada di tengah-tengah kapal berfungsi sebagai tempat dilaluinya tali kolor pada saat penarikan tali kolor dan sebagai tempat untuk menggantung cincin apabila cincin sudah terkumpul di samping kapal. Boom yang sama juga akan digunakan untuk mengangkat hasil tangkapan. Boom yang lain berfungsi untuk menaikkan dan menurunkan skiff boat, serta digunakan untuk menarik alat tangkap dari air ke atas kapal. Pada ujung-ujung boom digantung block sebagai tempat lewatnya tali menuju mesin takal.

\section{Pengoperasian soma pajeko}

Tahap awal operasi penangkapan dimulai dengan dua atau tiga orang ABK (Anak Buah Kapal) turun ke skiff boat menuju rumpon untuk mengamati pergerakan gerombolan ikan sekaligus melepas gara-gara yang ada pada rumpon dan mengikatkannya ke skiff boat. Kemudian kapal akan menjauhkan rumpon dan bergerak mengitari skiff boat dengan membuat gerak melingkar. Kapal akan bergerak ke posisi tertentu berdasarkan pertimbangan arah arus dan angin, dengan tujuan agar posisi bagian dalam kantong jaring menghadang arah arus dan posisi kapal menghadang arah angin. Penawuran alat tangkap dimulai, dimana kapal akan membentuk gerak melingkar dengan cepat berlawanan arah jarum jam dengan menurunkan pemberat, diikuti jaring, pelampung dan pelampung tanda yang berada pada bagian sayap jaring, kemudian pelampung, jaring, pemberat, cincin, dan tali kolor, dan setiap bagian jaring akan turun secara bersamaan sampai pada tali tarik dan kapal akan kembali pada pelampung tanda yang diturunkan. Setelah selesai penawuran jaring, dilakukan penarikan tali kolor dengan menggunakan mesin takal sampai semua cincin berkumpul di samping kapal. Selesai penarikan tali kolor, dilanjutkan dengan penarikan jaring dari kedua sayap sampai pada bagian kantong jaring dengan bantuan mesin takal.
Kemudian dilakukan pengangkatan hasil tangkapan sampai selesai diteruskan dengan pengikatan kembali gara gara dan penataan alat tangkap di buritan kapal.

\section{Hasil pengukuran faktor teknis dan faktor osea- nografi}

Pengukuran faktor teknis dan faktor oseanografi dilakukan pada 8 kali operasi penangkapan. Hasil pengukuran tersebut ditampilkan pada Tabel 1 dan Gbr. 1.

\section{Pembahasan}

Menurut Katiandagho (1989) bahwa untuk menangkap sekelompok ikan, maka pukat cincin harus dapat memenuhi tiga keadaan berikut, yaitu: (1) Melingkari gerombolan ikan secara horisontal, (2) Memagari secara vertikal dari permukaan laut hingga suatu kedalaman dimana ikan sukar keluar dari lingkaran jaring, (3) Mengurung gerombolan ikan dengan menutup bagian bawah jaring dengan menarik tali cincin.

Kelajuan melingkar jaring secara umum memiliki kecenderungan semakin menurun dan hasil tangkapan cenderung semakin meningkat. Pada setiap operasi dapat dilihat bahwa kelajuan pelingkaran jaring yang cenderung semakin lama, maka hasil tangkapan yang diperoleh akan cenderung meningkat. Selesai penawuran jaring biasanya langsung diikuti dengan penarikan tali kolor. Dalam hal ini yang perlu untuk diperhitungkan adalah lama waktu yang dibutuhkan sampai jaring benar-benar sudah tidak tenggelam lagi, dimulai pada saat jaring ditawurkan, agar secepatnya dilakukan penarikan tali kolor.

Panjang tali pemberat lebih pendek dari tali pelampung, menyebabkan jaring akan semakin lama turun ke dalam air, demikian juga jaring pada bagian sayap, bahu dan perut lebih panjang dari jaring pada bagian kantong, mengakibatkan luasan jaring yang mendapat gesekan dari air akan lebih banyak pada jaring bagian sayap, bahu dan perut sehingga jaring akan semakin lama turun ke dalam air dan dapat menyebabkan terbelitnya jaring pada tali kolor. Kelajuan melingkar alat tangkap memiliki pengaruh yang kecil pada saat pengoperasian karena ikan-ikan yang menjadi tujuan penangkapan sudah terkonsentrasi di bawah skiff boat dan diharapkan tidak terganggu pada saat pengoperasian dengan memperhatikan jarak antara lintasan penawuran jaring dengan gerombolan ikan. 
Tabel 1. Hasil pengukuran faktor teknis dan faktor oseanografi

\begin{tabular}{|c|c|c|c|c|c|c|c|c|c|c|c|c|c|}
\hline \multirow[t]{2}{*}{ Operasi } & \multirow[t]{2}{*}{ Tanggal } & \multirow{2}{*}{$\begin{array}{c}\text { Laju } \\
\text { lingkar } \\
(\mathrm{m} / \mathrm{s})\end{array}$} & \multirow{2}{*}{$\begin{array}{l}\text { Laju tarik } \\
\text { tali kolor } \\
(\mathrm{m} / \mathrm{s})\end{array}$} & \multicolumn{2}{|c|}{ Arus } & \multirow{2}{*}{$\begin{array}{l}\text { Suhu, } \\
\left({ }^{\circ} \mathrm{C}\right)\end{array}$} & \multirow[t]{2}{*}{ Salinitas } & \multicolumn{6}{|c|}{ Hasil Tangkapan (ton) } \\
\hline & & & & $\begin{array}{c}\text { Arah } \\
\left({ }^{\circ}\right)\end{array}$ & $\begin{array}{l}\mathrm{Kec} . \\
(\mathrm{m} / \mathrm{s})\end{array}$ & & & Tongkol & Cakalang & Layang & Selar & Tuna & Total \\
\hline 1. & $03 / 11 / 2012$ & 1,95 & 0,86 & 315 & 0,14 & 27,8 & 37 & - & - & 0,32 & 0,08 & - & 0,40 \\
\hline 2. & $04 / 11 / 2012$ & 1,91 & 0,75 & 67 & 0,14 & 27,8 & 37 & - & - & - & 0,08 & - & 0,08 \\
\hline 3. & $05 / 11 / 2012$ & 1,87 & 0,87 & 315 & 0,15 & 27,8 & 37 & 1,20 & 0,24 & - & - & 0,16 & 1,60 \\
\hline 4. & $11 / 11 / 2012$ & 2,08 & 0,71 & 180 & 0,65 & 28,0 & 37 & 0,16 & - & 0,32 & 0,16 & 0,08 & 0,72 \\
\hline 5. & $12 / 11 / 2012$ & 1,80 & 0,76 & 135 & 0,52 & 28,1 & 37 & 1,60 & - & 0,08 & 0,08 & 0,08 & 1,84 \\
\hline 6. & $13 / 11 / 2012$ & 1,78 & 0,83 & 135 & 0,18 & 28,1 & 37 & 0,16 & 2,00 & 0,16 & 0,08 & - & 2,40 \\
\hline 7. & $14 / 11 / 2012$ & 1,00 & 0,59 & 90 & 0,15 & 28,1 & 37 & 0,16 & - & 0,16 & 0,16 & - & 0,48 \\
\hline 8. & $15 / 01 / 3013$ & 1,88 & 0,79 & 45 & 0,76 & 28,0 & 37 & 480,00 & 0,72 & - & - & 0,24 & 8,96 \\
\hline
\end{tabular}

Kendala yang dialami pada operasi 2 yaitu jaring sobek pada sambungan antara bagian perut dan bagian kantong jaring. Hal ini terjadi pada saat penarikan jaring tiba di antara bagian perut dan bagian kantong yang menyebabkan banyak hasil tangkapan yang tumpah melalui celah tersebut. Pada operasi 4, arus yang kencang mendorong skiff boat lebih dekat ke kantong jaring pada saat penawuran jaring sehingga ikan-ikan di bawah skiff boat terganggu dan melarikan diri dari lingkaran jaring. Pada operasi 7 ada bagian jaring pada sayap jaring yang terbelit pada tali kolor. Kendala-kendala tersebut menyebabkan hasil tangkapan yang diperoleh sedikit.

Setiap operasi penangkapan dengan kelajuan penarikan tali kolor yang lebih cepat menunjukkan hasil tangkapan yang diperoleh akan semakin banyak. Berarti bahwa kelajuan penarikan tali kolor memiliki pengaruh yang besar terhadap hasil tangkapan karena pada saat penarikan, tali kolor akan melewati tepat di bawah gerombolan ikan sehingga kecepatan penarikan tali kolor yang lebih cepat akan lebih baik dan cepat menutup bagian bawah jaring dan memperkecil kemungkinan ikan untuk lolos dari bagian tersebut.

Pada operasi penangkapan ke 7 dengan hasil tangkapan sedikit yaitu 0,48 ton, terjadi kendala berupa jaring terbelit pada tali kolor sehingga penarikan hanya dilakukan pada satu arah saja. Hal ini membutuhkan waktu yang lama dalam penarikan tali kolor. Secara teori, agar jaring tidak terbelit pada tali kolor seharusnya tali pemberat harus lebih panjang dari tali pelampung karena pada bagian sayap, tali pemberat yang dibutuhkan lebih panjang karena adanya pemotongan miring (tapering).
Terbelitnya jaring pada tali kolor selain diakibatkan oleh konstruksi alat tangkap yang tidak sesuai yaitu panjang tali pemberat lebih pendek dari tali pelampung, tali kolor yang digunakan adalah tali PE yang massa jenisnya $(0,96)$ lebih kecil dari massa jenis air laut $(1,025)$ sehingga tali kolor akan mengapung. Selain itu, pada bagian sayap antara tiap lembaran jaring dibuat dengan tidak menggunakan pemotongan miring (tapering). Nelayan membuat bagian ini dengan lacing dan menggunakan gathering pada saat penyambungan lembaran jaring (kendala pada operasi 2, lacing putus, jaring terbuka dan hasil tangkapan tertumpah keluar), sehingga pada saat bagian bawah jaring terentang di air, ada bagian bawah jaring yang tergantung dan tidak terentang dengan sempurna, mengakibatkan jaring terbelit pada tali kolor.

Penentuan besar kecil radius pelingkaran alat tangkap adalah dengan mengetahui kedalaman gerombolan ikan dan jenis ikan yang menjadi target tangkapan. Untuk mengetahui kedalaman gerombolan ikan dan jenis ikan yang menjadi target tangkapan nelayan menggunakan pancing tangan. Dari pengalaman nelayan, ukuran lingkaran penawuran jaring bergantung pada jenis ikan yang akan ditangkap. Untuk gerombolan ikan tongkol (Auxis thazard) dan ikan layang (Decapterus macarellus), jaring ditawurkan membentuk lingkaran sebesar mungkin sedangkan untuk ikan selar (Selaroides leptolepis), pelingkaran jaring tidak perlu terlalu lebar karena distribusi ikan selar adalah bergerombol menyelam ke dalam kolom air dan tidak menyebar di permukaan. 


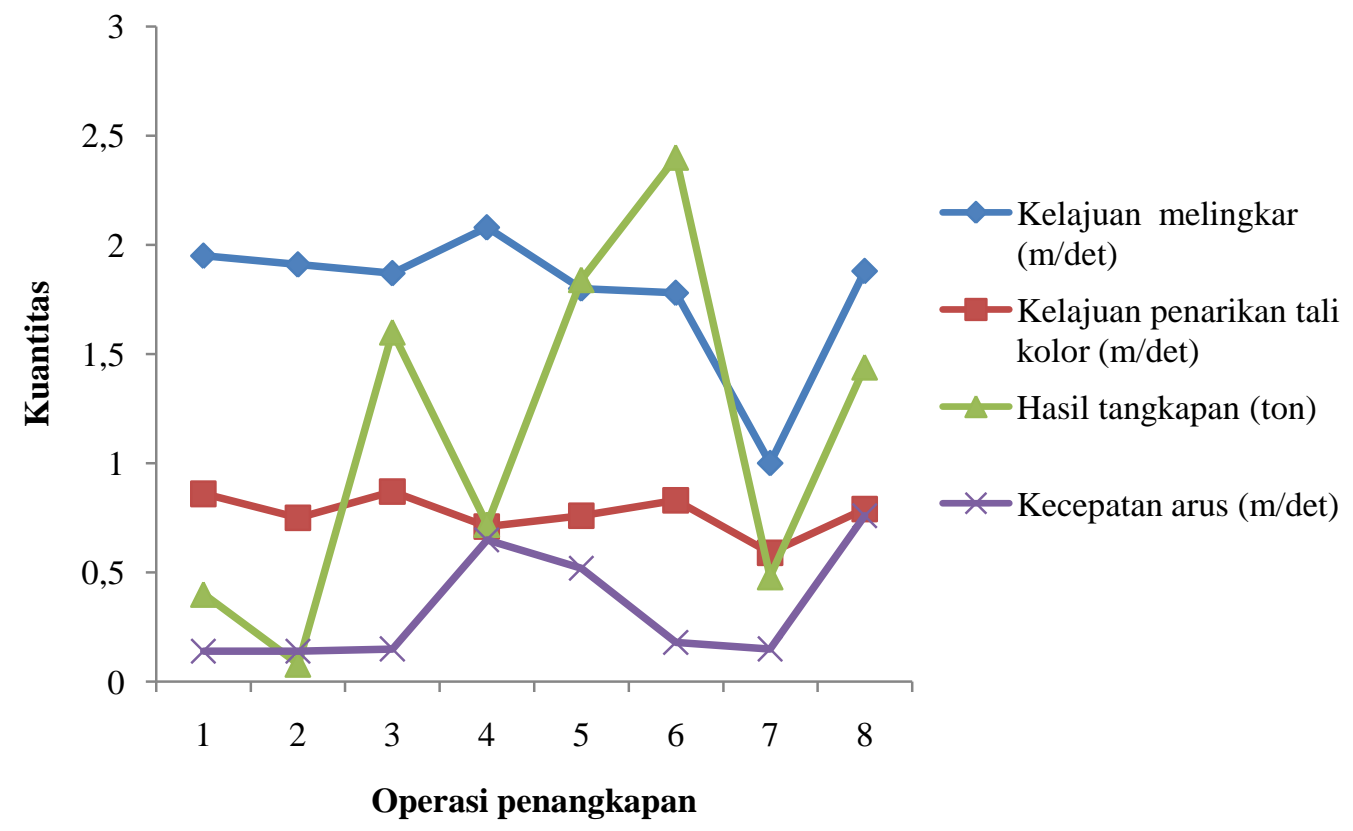

Gambar 1. Grafik faktor teknis operasi dan faktor oceanografi

Arah arus menjadi faktor pertimbangan yang penting bagi nakhoda pada saat penawuran jaring dilakukan. Kapal akan mengikuti arus pada saat mulai melingkar, nakhoda harus menentukan kedudukan alat tangkap, dimana bagian kantong harus berada di bawah arus sehingga alat tangkap tepat menghadang arah arus pada saat penawuran kantong dan jaring terbuka dengan benar. Penentuan radius lingkaran apabila tidak memperhitungkan kecepatan arus maka selama penawuran, arus mendorong skiff boat dekat dengan jaring pada bagian kantong (operasi 4), sehingga mengganggu kelompok ikan yang berada dibawah skiff boat dan dapat menyebabkan ikan melarikan diri. Kecepatan arus memenuhi syarat seperti yang dianjurkan oleh Katiandagho dan Kumajas (1987) yaitu < 0,5 knot $(\mathrm{kn}, 1$ knot $=$ $0,514 \mathrm{~m} / \mathrm{s}$ ) pada operasi $1,2,3,6$, dan 7 , sedangkan pada operasi 4,5 , dan 8 , kecepatan arus lebih cepat dari yang dianjurkan. Dari beberapa operasi yang memenuhi syarat kecepatan arus ternyata ada hasil tangkapan dengan jumlah yang sedikit, begitu juga pada kecepatan arus melebihi kecepatan arus seperti yang dianjurkan justru memperoleh hasil tangkapan yang banyak. Pada saat pengoperasian walaupun arus yang kuat tetapi nakhoda memperhitungkannya dengan baik, dan konsentrasi ikan di bawah skiff boat pada saat itu juga banyak, sehingga memperoleh hasil tangkapan banyak juga.

Suhu permukaan di rumpon yaitu berkisar $26,5^{\circ} \mathrm{C}-28,5^{\circ} \mathrm{C}$ (Katiandagho, 1990) sangat baik untuk penangkapan ikan-ikan pelagis kecil yang biasanya bergerombol dan dekat dengan permukaan air sehingga mudah untuk ditangkap dengan alat tangkap soma pajeko. Selama pengoperasian soma pajeko suhu permukaan berkisar antara $27,8^{\circ} \mathrm{C}-28,1^{\circ} \mathrm{C}$.

Salinitas adalah konsentrasi garam-garam yang terdapat di perairan. Hasil pengukuran salinitas pada setiap operasi menunjukkan hasil yang sama yaitu 37, dengan demikian bahwa salinitas tersebut cocok dengan kondisi tubuh ikan-ikan hasil tangkapan dan memiliki ikan-ikan tersebut memiliki kisaran toleransi salinitas hingga 37.

Hasil tangkapan ikan pelagis kecil yaitu ikan layang, ikan selar, dan ikan tongkol. Ikan-ikan yang tertangkap ini adalah ikan-ikan dewasa yang sudah layak tangkap. Sedangkan hasil tangkapan berupa ikan-ikan pelagis besar seperti tuna sirip kuning (Thunus albacares) dan cakalang (Katsuwonus pelamis) adalah ikan-ikan muda yang belum layak tangkap. 
Selama melakukan pengoperasian soma pajeko, operasi yang paling baik pada operasi 6 dengan hasil tangkapan 2,4 ton yang mana kelajuan melingkar pada saat tersebut yaitu $1,78 \mathrm{~m} / \mathrm{det}$ paling rendah ke-2 dari setiap operasi dan kelajuan penarikan tali kolor yang cepat yaitu $0,83 \mathrm{~m} / \mathrm{det}$. Kemudian operasi 5 dengan hasil tangkapan 1,84 ton, dengan kelajuan melingkar $1,80 \mathrm{~m} / \mathrm{det}$ dan kelajuan melingkar $0,76 \mathrm{~m} / \mathrm{det}$. Ketrampilan nelayan yang baik dalam menentukan radius pelingkaran dan kerja sama semua ABK pada setiap tahapan pengoperasian menunjang pengoperasian ini sehingga berjalan dengan baik.

\section{KESIMPULAN}

Sukses pengoperasian soma pajeko dengan alat bantu rumpon tergantung pada kelajuan melingkar, kelajuan penarikan tali kolor, dan ketrampilan nelayan dalam pengoperasian. Semakin lama kelajuan melingkar, cenderung hasil tangkapan akan semakin meningkat, dan semakin lebih cepat kelajuan penarikan tali kolor, maka cenderung hasil tangkapan yang diperoleh akan lebih banyak. Operasi penangkapan yang paling baik yaitu pada operasi 6 yaitu 2,4 ton dan operasi 5 yaitu 1,84 ton.
Arus, suhu dan salinitas ikut mempengaruhi sukses pengoperasian, dimana kedudukan alat tangkap harus tepat berada di bawah arus. Suhu yang baik untuk penangkapan ikan pelagis kecil berkisar antara $26,5^{\circ} \mathrm{C}-28,5^{\circ} \mathrm{C}$, selama operasi penangkapan, suhu yang diukur berkisar antara $27,8^{\circ} \mathrm{C}-28,1^{\circ} \mathrm{C}$ dengan salinitas pengukuran yang sama yaitu 37 .

Jenis hasil tangkapan yang diperoleh yaitu ikan tongkol, ikan cakalang, ikan layang, ikan selar dan ikan tuna, dan yang paling banyak tertangkap yaitu ikan tongkol dan ikan cakalang.

\section{DAFTAR PUSTAKA}

Katiandaho, E.M. dan H.J. Kumajas. 1987. Metode Penangkapan Ikan. Fakultas Perikanan dan Ilmu Kelautan Universitas Sam Ratulangi, Manado.

Katiandagho, E.M. 1989. Purse Seine. Fakultas Perikanan Universitas Sam Ratulangi Manado.

Katiandagho, E.M. 1990. Migrasi vertikal harian ikan pelagis kecil yang diamati di bawah rumpon di perairan Momalia Kabupaten Bolaang Mongondow, Propinsi Sulawesi Utara. Jurnal Fakultas Perikanan Universitas Sam Ratulangi Manado 1(3): 218-228.

Nomura, M. dan T. Yamazaki. 1977. Fishing Techniques 1. Japan International Cooperation Agency, Tokyo.

Sears, F.W. dan P.J. Soedarjana. 1970. Mekanika, Panas dan Bunyi. Bina Cipta, Jakarta. 